\title{
The effects of presenting oncologic information in terms of opposites in a medical context
}

This article was published in the following Dove Press journal:

Patient Preference and Adherence

\section{Roberto Burro' \\ Ugo Savardi' \\ Maria Antonietta \\ Annunziata ${ }^{2}$ \\ Paolo De Paoli \\ Ivana Bianchi ${ }^{3}$}

'Department of Human Sciences, University of Verona, Verona, Italy; ${ }^{2}$ National Cancer Institute IRCCS 'Centro di Riferimento Oncologico' (CRO), Aviano, Italy; ${ }^{3}$ Department of Humanities (Section Philosophy and Human Sciences), University of Macerata, Macerata, Italy
Correspondence: Roberto Burro Department of Human Sciences, University of Verona, Lungadige Porta Vittoria 27, 37129 Verona, Italy Email roberto.burro@univr.it
Background: An extensive body of literature has demonstrated that many patients who have been asked to participate in clinical trials do not fully understand the informed consent forms. A parallel independent study has demonstrated that opposites have a special status in human cognitive organization: they are common to all-natural languages and are intuitively and naturally understood and learnt.

Purpose: The study investigates whether, and how, the use of opposites impacts on doctorpatient communication: does using the terms "small-large" to describe a nodule (ie, bipolar communication) rather than speaking in terms of centimeters (ie, unipolar communication) affect a patient's understanding of the situation? And is it better to speak of "common-rare" side effects (ie, bipolar communication) instead of the number of people who have suffered from particular side effects (ie, unipolar communication)?

Methods: Two questionnaires were created and used, one presenting the information in terms of opposites (ie, bipolar communication) and another using unipolar communication.

Results: The participants' perception of their situation (in terms of feeling healthy-ill, being at high-low risk, and their treatment requiring high-low commitment) varied in the two conditions. Moreover, self-reported levels of understanding and satisfaction with how the information was communicated were higher when opposites were used.

Limitations: Since this is the first study that addresses the merits of using bipolar structures versus unipolar structures in doctor-patient communication, further work is needed to consolidate and expand on the results, involving not only simulated but also real diagnostic contexts.

Conclusion: The encouraging results imply that further testing of the use of opposites in informed consent forms and in doctor-patient communication is strongly advisable.

Keywords: opposites, bipolar, unipolar, informed consent, doctor-patient communication, understanding, satisfaction

\section{Introduction}

Clinical trials have a central role in terms of providing evidence to support oncologic treatments. In the USA, the National Cancer Institute (NCI) National Clinical Trials Network has estimated that between 19,000 and 20,000 patients enrolled in clinical trials in 2016, and the number of participants in the European Union has substantially increased over the past decade (revision of the "Clinical Trials directive", 2011). ${ }^{1}$ Informed consent is an important part of the enrollment process. Ethical aspects related to informed consent include the completeness and adequacy of the information provided. An extensive body of literature has demonstrated that many people do not understand the detailed information contained in informed consent forms and therefore are also to some extent unaware of the risks incurred by their exposure to the treatments. ${ }^{2-8} \mathrm{Com}-$ prehension of and satisfaction with informed consent forms are, in general, particularly 
limited in the case of people with a lower standard of secondary education, even when simple language is used..$^{9-11}$

Deciding to take part in a clinical trial is an individual choice. However, participation rates in clinical trials for cancer treatments are affected not only by a patient's attitudes toward the trial but also by the organizer's ability to communicate with the patient. ${ }^{12-14}$ A variety of strategies such as short films, phone- or web-based decision aiding tools, and supplementary discussions with a member of the research team who is not a physician have been proposed as a way of improving patient knowledge and increasing their understanding of informed consent forms. ${ }^{15-25}$ In any case, it has been generally acknowledged that it is necessary to develop strategies to improve the communication skills of the organizers of clinical trials..$^{9,16,26}$

\section{From cognitive dimensions to communication: the role of opposites}

The way in which information is presented for the purposes of informed consent, and in doctor-patient communication in general, usually ignores the fact that humans perceive, ${ }^{27-32}$ conceptualize, ${ }^{33-35}$ and linguistically describe ${ }^{36-38}$ their experiences in terms of opposites.

It has been widely acknowledged that opposites have a special status in human cognitive organization. They play a significant role in the mental lexicon and are intuitively and naturally understood and learnt. ${ }^{39-43}$ They are primal schemas in cognitive development, ${ }^{44-48}$ and they constitute a primal relation in the perceptual experiences of adults. ${ }^{28,49-51}$

Given that opposites are primal and pervasive in direct experiences and natural language, our hypothesis is that they might also enhance the comprehension of information provided in a diagnostic context. If naïve subjects naturally process information in terms of polarized dimensions, they might also re-elaborate in terms of opposites what a doctor is saying. This would mean, for example, that when a doctor conveys information concerning the extent of an area affected by a disease in terms of centimeters, patients might carry out a real-time transformation in their minds in terms of small (at various gradations) versus big (at various gradations). Similarly, when information concerning the number of treatment sessions that are required or the duration of the treatment or the number of instances when serious side effects occur is given, patients might recode these pieces of information in terms of few-many sessions, long-short duration, and rarecommon incidences of serious side effects, respectively. If this is the picture that they mentally establish while listening to the doctor, it will probably also be the internal mind-set they will use to re-narrate the situation to themselves and to their relatives and friends, thus consolidating this mental representation. The latter is, of course, a hypothesis that can and should be tested experimentally. In the context of this study, we take this hypothesis as a general framework and will also test some related hypotheses. But before presenting these in detail, we want to clarify that in this paper, when we speak of bipolar dimensions or opposites, we do not mean binary dimensions or binary oppositions (ie, dimensions formed by only two values). From a perceptual and cognitive point of view, bipolar dimensions are usually mentally graded at one or both poles, and in most of the cases, there are also intermediate experiences that are identified as being "neither one pole, nor the other", for example, neither big nor small, neither long nor short, neither painful nor pleasant, etc. ${ }^{27,29-31}$ In this sense, opposites are not simplistic structures that cannot support intensity gradations. As such, they do not contrast the modulated communication required in oncological diagnoses; they simply locate these modulations in a polarized frame which is more natural and therefore easier to understand.

\section{The study}

\section{Aims}

To the best of our knowledge, the present study is the first to evaluate the role of opposites in modeling the understanding of medical information. Specifically, using a simulated oncologic diagnostic context, we investigated how a person's perception of his/her health condition and the risks and commitment relating to any treatment required varies when information is communicated using opposite terms (eg, rarecommon, small-big) as opposed to unipolar linguistic structures (see below the two different types of unipolar structures commonly associated with "4-item configurations" and "3-item configurations"). If a doctor talks of a small-large nodule (ie, a bipolar structure) instead of talking in terms of centimeters (ie, a unipolar structure) or of common-rare side effects (ie, bipolar) instead of talking of the number of people who suffer a particular side effect (ie, unipolar), how does this impact on the patient's understanding?

In particular, we will investigate the following:

1. Any changes in the patient's perception of being healthy versus ill, at low versus high risk, and feeling slightly versus maximally committed to the treatment when information is provided with as compared to without reference to opposites.

2. Any differences between the two cases in the overall satisfaction with how the information was communicated and in self-reported levels of understanding. 
Since clear understanding of the situation is essential not only for ethical reasons but also to guarantee the patient's conscious involvement in all the phases of the treatment, higher ratings of self-reported understanding and satisfaction with how the information is conveyed will be regarded as desirable results. Similarly, since the patient's active engagement is considered essential in cases of oncologic diseases in terms of facing the situation and making decisions regarding the treatment, enhancing the person's "arousal" (within a reasonable range) has to be considered desirable.

\section{Methods}

\section{Preliminary phase}

A set of basic information to be communicated was defined, and two questionnaires to be used in the main research phase were created.

Using inter-observation sessions (with a total of 22 hours of inter-observation), three experts (U Savardi, I Bianchi and R Burro, all authors of this paper) analyzed the contents of various standard informed consent forms and studied a series of videos produced by the psychology department and medical staff of the National Cancer Institute CRO (Aviano, Italy). These videos simulate typical, realistic dialogues between doctors and patients in diagnostic and follow-up settings. The "patient" was an adult female (an actress) who interacted with 10 real doctors (employed at the CRO Institute) in various role-play settings corresponding to first diagnosis, treatment, and follow-up. The videos were judged by the members of the research group working in the CRO institution (Drs M A Annunziata and P De Paoli) to be highly realistic in that they represented typical conversations. The analysis revealed a systematic lack of attention with regard to whether information was conveyed using bipolar or unipolar structures. Other aspects were clearly important to the doctors as seen in the videos, such as their desire to convey information concerning the patient's situation and the proposed treatment and to establish the right empathic approach with a view to actively involve patients in the decision-making process. But the two types of structure (bipolar and unipolar) varied randomly within the conversations.

A list of statements were drawn up by the three experts, which included the various types of information frequently referred to by the doctors and enquired about by the patients in the videos in addition to the information found in standard informed consent forms. In order to establish a set of stimuli, corresponding versions of each piece of information were created following two criteria as described below using the terms "4-item configuration" and "3-item configuration".
These correspond to the two alternative ways in which one can give information without mentioning opposites. For example, instead of saying that "the tests revealed the existence of a large nodule" or "of a small nodule", that is, communicating by means of opposites, the doctor might report the size of the nodule in centimeters (in this way to avoid any references to opposites) or he/she might simply say that "the tests revealed the existence of a nodule", without mentioning the size, and again avoiding any references to opposites. But in the latter case, by not providing any information which would shift the balance toward one or the other pole, the communications remains - at least in theory - in a neutral position.

1.4-item configuration (Figure 1A). For each two bipolar item, there were two items expressing the same information using a unipolar scale, hence the term "4-item configuration". For example, the two items with information concerning the size of a nodule which are expressed in bipolar terms by means of small-large (eg, "The medical tests have revealed the presence of a small nodule"; "The medical tests have revealed the presence of a large nodule") were expressed in centimeters in the corresponding unipolar version (eg, "The medical tests have revealed the presence of a nodule of $1 \mathrm{~cm}$ "; "The medical tests have revealed the presence of a nodule of $7 \mathrm{~cm}$ "). Information concerning survival rates which was expressed in terms of high-low in the bipolar version (eg, "There are low survival rates associated with this disease"; "There are high survival rates associated with this disease") was expressed in percentages in the unipolar version (eg, "There is a $30 \%$ survival rate associated with this disease"; "There is a $70 \%$ survival rate associated with this disease"). The incidence of the disease in the population which was expressed in bipolar terms by rare-common (eg, "The nodule that you have is rare"; "The nodule that you have is common") was expressed in the unipolar version as a proportion (eg, "The nodule that you have affects 1 in a million people"; "The nodule that you have affects 1 in a thousand people").

2. 3-item configuration (Figure 1B). This is again a unipolar communication in that any references to either of the two poles is avoided. For example, the doctor informs the patient about the existence of a nodule ("The medical tests have revealed the presence of a nodule") without specifying whether the nodule is benign or malignant. Similarly, the presence of side effects associated with the treatment is mentioned without any statement concerning whether the side effects are minor or severe ("The standard treatment for this tumor produces side effects"). Here we see that there is a single item in the unipolar version and 
A

Size:

Survival rates:

Incidence of disease:

Probability of adverse side effects of treatment:

Duration of treatment:

Size:

Survival rates:

Incidence of disease:

Probability of adverse side effects of treatment:

Duration of treatment:

$\begin{array}{ll}\text { UNI+ } & \text { UNI- } \\ 1.3 \mathrm{~cm}(0.5 \text { inch }) & 7.6 \mathrm{~cm} \text { (3 inch) } \\ 70 \% & 30 \% \\ 1 \text { in a thousand } & 1 \text { in a million } \\ 1 \text { in } 100,000 & 1 \text { in } 100 \\ 15 \text { days } & 1 \text { year } \\ & \\ \text { BIP+ } & \text { BIP- } \\ \text { Small } & \text { Large } \\ \text { High } & \text { Low } \\ \text { Common } & \text { Rare } \\ \text { Low } & \text { High } \\ \text { Short } & \text { Long }\end{array}$

B

Disease: presence of a nodule

Adverse side effects of treatment: presence

Type of treatment: administered in cycles

Place of treatment: medical facility

Impact of treatment on ability to work:

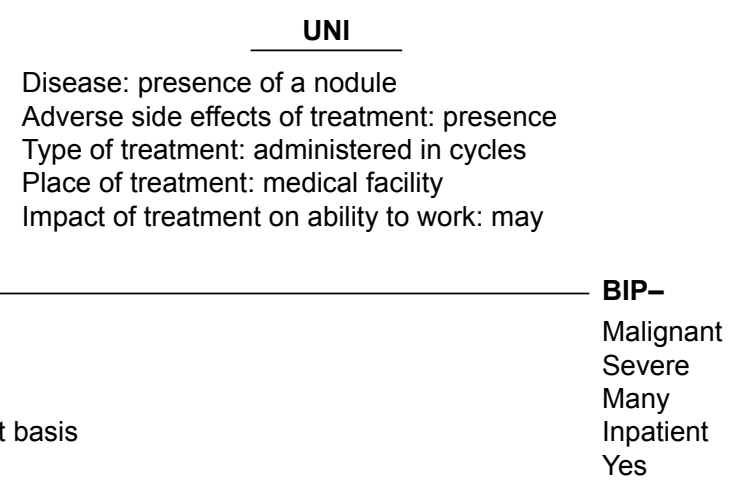

Figure I The two types of "correspondence" between unipolar and bipolar communication: the 4-item configuration (A) and the 3-item configuration (B). When opposites are used, one relates to the positive pole $(+)$, the other to the negative pole $(-)$.

Abbreviations: UNI, unipolar; BIP, bipolar.

two items in the bipolar version, hence the term " 3 -item configuration".

Two different questionnaires were drawn up from this list of items, one containing only information expressed using unipolar structures (from now on, UNI) and comprising 34 items ( 20 items belonging to the 4-item configuration and 14 items belonging to the 3 -item configuration) and the other containing only information expressed using bipolar structures (from now on, BIP) and comprising 48 items (20 items belonging to the 4 -item configuration and 28 items belonging to the 3 -item configuration).

The two sets of items are presented in Table S1. The issues addressed concerned the nature of the disease, the characteristics of the treatment, and the quality of life to be expected during and after treatment. In the BIP version, the statements included:

1. For the disease (nodule): small-large, benign-malignant, localized-widespread, common-rare, slow-quick progressing, high-low genetic predisposition, easy-hard to treat, high-low survival rates.

2. For the treatment: definitive-palliative, high-low efficacy, advisable-necessary, short-long duration, one-many cycle(s), outpatient-inpatient (hospitalization), high-low probability of side effects, minor-severe side effects, immediate-delayed onset of side effects, temporarypermanent duration of side effects.

3. For the quality of life: autonomous-assisted living during the treatment, autonomous-assisted living after the treatment, invariant-changed lifestyle during the treatment, invariant-changed lifestyle after the treatment, yes-no effect on the ability to work during the treatment, yes-no effect on the ability to work after the treatment.

\section{Main phase}

The two questionnaires (UNI, BIP) were presented individually to two different groups of Italian participants.

A hypothetical scenario was described in the instructions:

"Imagine that your doctor has recommended that you have some medical tests at a center specialized in oncologic diagnosis in order to ascertain whether or not you have a health problem. You have done the tests and now you are talking to the doctor who tells you what the situation is.

During the interview, he/she gives you various pieces of information. Express your judgment of each piece of information received in terms of 
1) how healthy-ill you are

2) how high-low the risks involved in the treatment are

3) how high-low the commitment required by the treatment will be".

Three ratings were given by participants using three continuous bipolar scales ( $100 \mathrm{~mm}$ long) which were defined at the extremes by the following labels: completely healthyextremely ill (referring to the perception of the state of health, from now on $\mathrm{H}$ ); zero risk-extremely high risk (referring to perception of risk, from now on R); low commitment-high commitment (referring to the perception of the commitment required by the treatment, from now on $\mathrm{T}$ ).

Participants were instructed to consider each piece of information individually, in isolation from the previous statements and not cumulatively. "For example, if one sentence says something about the size of the nodule (eg, it's small) and then the following sentence says something about whether it is benign/malignant (eg, it's malignant), do not add this second piece of information to the first (ie, the doctor was saying that you have a small malignant nodule)".

At the end of the questionnaire, participants were asked to rate (using a scale from $0 \%$ to $100 \%$ ) how far they had understood the information provided ("How much of the information provided by the doctor do you think you understood?") and their overall satisfaction regarding the clarity of the communication ("How satisfied are you with the clarity of communication?").

\section{Participants}

A total of 470 Italian undergraduate students and adults were divided into two groups: 235 participated in the BIP condition, with the bipolar questionnaire (136 female and 99 male participants; mean age: 26.3 years, $\mathrm{SD}=8.44$ ) and 235 participated in the UNI condition, with the unipolar questionnaire (143 female and 92 male participants; mean age: 25.5 years, $\mathrm{SD}=9.21$ ). The study complied with the Helsinki ethics protocol and was approved by the Ethics Committee of the University of Verona (where the data were collected). Participants volunteered in the study. They were recruited in non-medical university faculties (in libraries, study halls, and the campus) and randomly assigned to one of the two conditions. Written informed consent was provided by each participant.

\section{Statistical analyses}

Responses were analyzed using mixed-effect models, ${ }^{52}$ with Gaussian family and identity link functions. In cases involving significant main effects or interactions, post hoc tests using the Bonferroni correction were conducted and estimates of the nonstandardized size of the effect (EST, ie, the regression coefficient) and Cohen's index (d) as the standardized size of the effect were reported. ${ }^{53-56}$ Mixed regression assumptions (including the assumption that residuals are normally distributed and homoscedastic) were checked using quantile comparison and residual diagnostic plots. The goodness-of-fit of the linear mixed models (LMMs) was assessed using the conditional $\mathrm{R}^{2}$ index..$^{57}$

All the analyses were carried out using the statistical software program R 3.3.1, with the "Ime4", "car", "lsmeans", and "effects" packages. We performed mixed model ANOVA tables (type 3 tests) via likelihood ratio tests implemented in the "afex" package.

\section{Results}

A series of analyses were conducted to assess whether changes in the participants' perception of being healthy versus ill (health axis, H), at low versus high risk (risk axis, R), and feeling slightly versus maximally committed to the treatment (treatment axis, T) occurred when information was provided with or without reference to opposites.

\section{General analysis}

First, we studied whether and how the rating given by participants depended on the variables used in the study, that is, type of communication (BIP, UNI), the axes used for evaluating the information provided $(\mathrm{H}, \mathrm{R}, \mathrm{T})$ and the configuration type (3-, 4-item configurations). A linear mixed model (Gaussian family) was carried out on the ratings given by participants to the entire set of items presented in the questionnaires, with type of communication, axes, and configuration type as fixed effects and participants as random effects. The assumptions of mixed regression models were verified (Figure 2). The conditional $\mathrm{R}^{2}$ index was equal to 0.34 .

Various significant effects emerged (Figure 3 ). The main effect of axes $\left(\chi_{(2, N=470)}^{2}=610.1556, p<0.0001\right.$; Figure 3A) suggested that the items elicited in general higher ratings on the axis relating to commitment to the treatment than on the other two axes.

The interaction between axes and configuration type $\left(\chi_{(2, N=470)}^{2}=51.5146, p<0.0001\right.$, Figure 3B) revealed that for items with a 3 -item configuration structure, the ratings in terms of risk and health did not differ ${ }_{3} \mathrm{R}-{ }_{3} \mathrm{H}$ : EST $=0.053$, $\mathrm{SE}=0.324$, t-ratio $=0.166, p=1.000, \mathrm{~d}=0.007 ;{ }_{3} \mathrm{~T}-{ }_{3} \mathrm{H}$ : $\mathrm{EST}=5.876, \mathrm{SE}=0.324$, t-ratio $=18.132, p<0.0001, \mathrm{~d}=0.836$; ${ }_{3} \mathrm{~T}-{ }_{3} \mathrm{R}: \mathrm{EST}=5.822, \mathrm{SE}=0.324$, t-ratio $=17.966, p<0.0001$, $\mathrm{d}=0.828$ ), whereas in the 4-item configuration, structure 

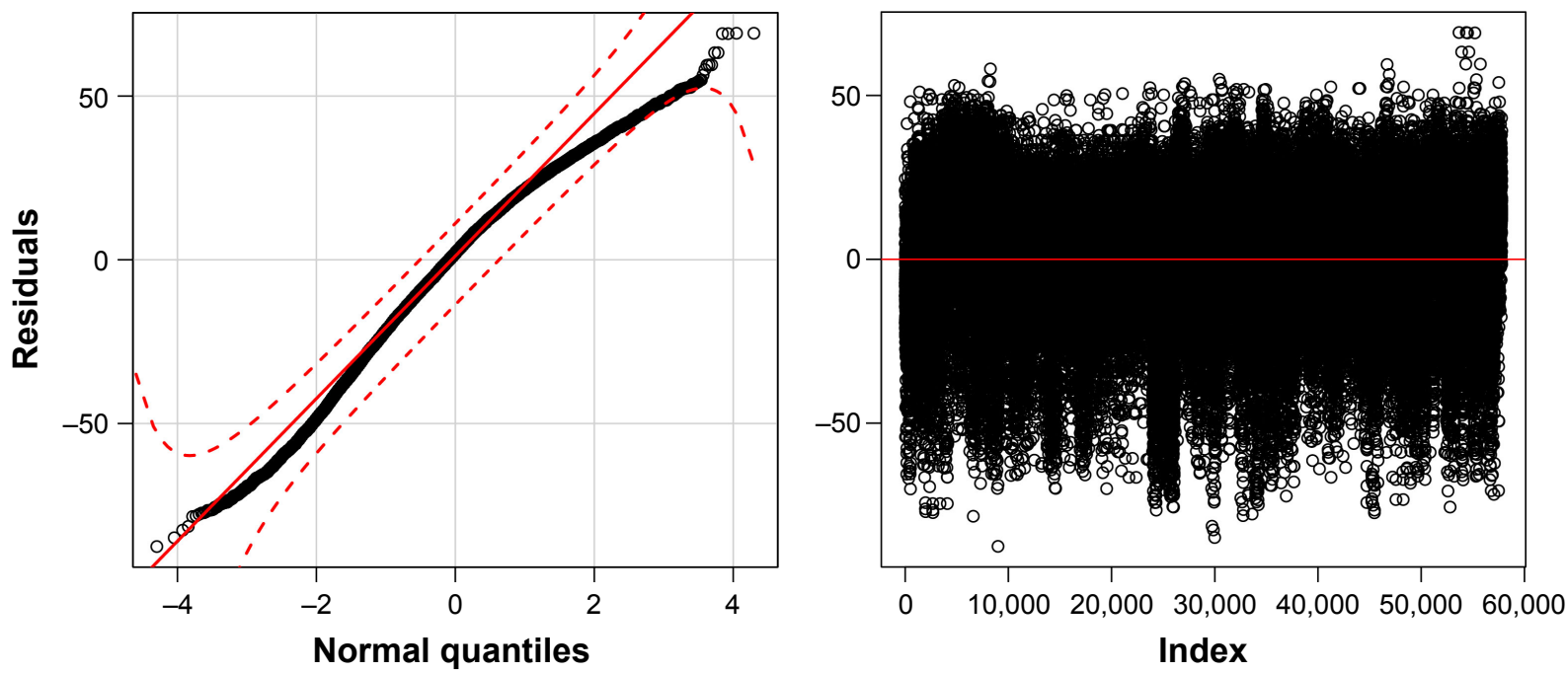

Figure 2 Diagnostic plots used for testing the mixed regression assumptions concerning the analysis of the ratings (linear mixed model) as described in the main text.

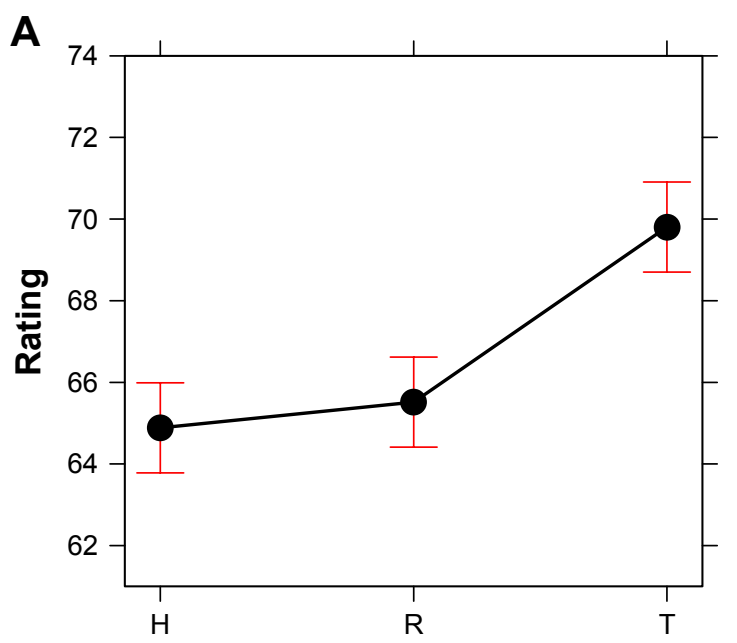

Axes

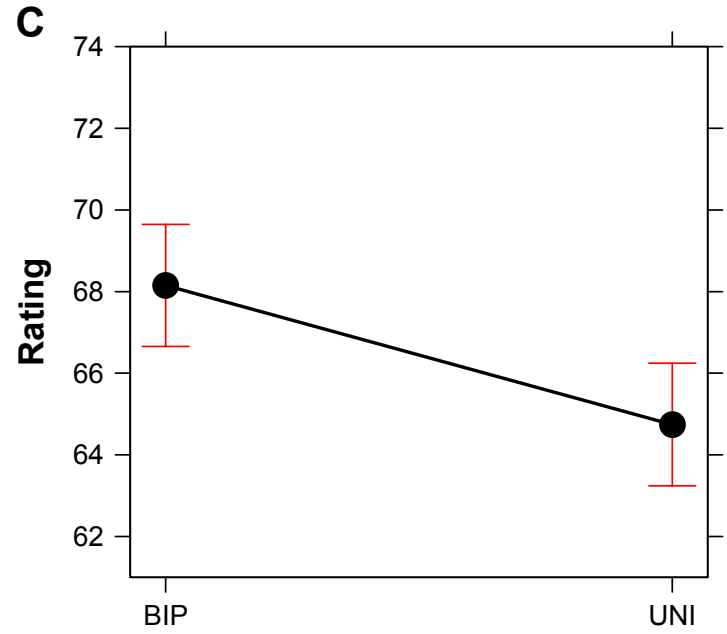

Type of communication

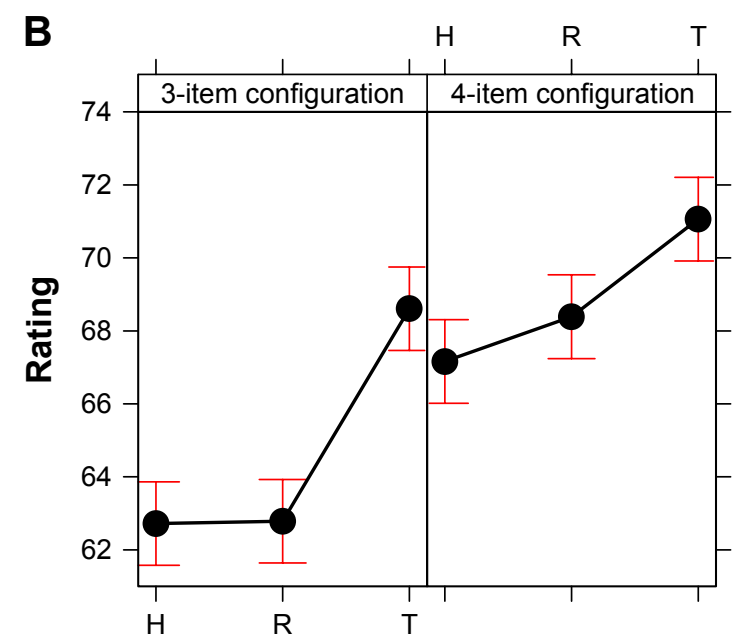

Axes

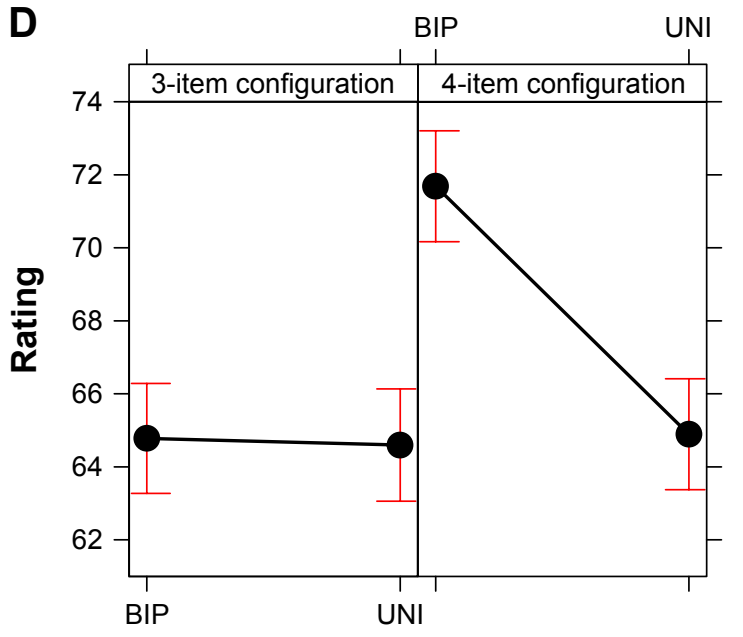

Type of communication

Figure 3 Effects of axes ( $\mathrm{H}, \mathrm{R}$ and $\mathrm{T})$ and type of communication (BIP; UNI) on the ratings. The main effects are reported in (A and $\mathbf{C})$. The interactions of each effect with configuration type (3-item, 4-item configuration) are shown in (B and $\mathbf{D})$. Error bars represent a $95 \%$ confidence interval.

Abbreviations: BIP, bipolar; $\mathrm{H}$, health; R, risk; T, commitment to the treatment; UNI, unipolar. 
ratings related to risk were higher than those given in the health axis $\left({ }_{4} \mathrm{R}-{ }_{4} \mathrm{H}: \mathrm{EST}=1.238, \mathrm{SE}=0.313\right.$, t-ratio $=3.957$, $p<0.001, \mathrm{~d}=0.200 ;{ }_{4} \mathrm{~T}-{ }_{4} \mathrm{H}: \mathrm{EST}=3.987, \mathrm{SE}=0.313$, t-ratio $=12.735, p<0.0001, \mathrm{~d}=0.587 ;{ }_{4} \mathrm{~T}-{ }_{4} \mathrm{R}: \mathrm{EST}=2.748$, $\mathrm{SE}=0.313$, t-ratio $=8.777, p<0.0001, \mathrm{~d}=0.405$ ).

Significantly (in terms of the hypothesis underlying this study), a main effect of type of communication also emerged $\left(\chi_{(1, N=470)}^{2}=11.089, p=0.0008\right.$, Figure $\left.3 C\right)$ suggesting that $\mathrm{BIP}$ ratings were higher than UNI ratings. However, there was a significant interaction between type of communication and configuration type $\left(\chi_{(1, \mathrm{~N}=470)}^{2}=323.025, p<0.0001\right)$, and this indicated that in the case of 4 -item configurations, BIP communication was specifically associated with higher ratings than UNI communication (4-item: BIP vs UNI = $\mathrm{EST}=6.794, \mathrm{SE}=1.096$, $\mathrm{t}$-ratio $=6.198, p<0.0001, \mathrm{~d}=0.290$ ) whereas with 3 -item configurations no overall difference emerged (Figure 3D).

This initial analysis provided first indications that the ratings varied depending on whether a BIP or UNI communication type was used, but it also showed that the effect was modulated by the configuration type used. Further in-depth analyses were thus carried out separately on the subset of items characterized by a 4-item configuration and on the subset of items characterized by a 3-item configuration.

\section{Analysis of the 4-item configuration type}

By analyzing the responses to 4-item configurations, it was possible to test, first, whether information relating to the positive pole of a dimension elicited (as expected) a different perception in terms of health, risk, and commitment as compared

A

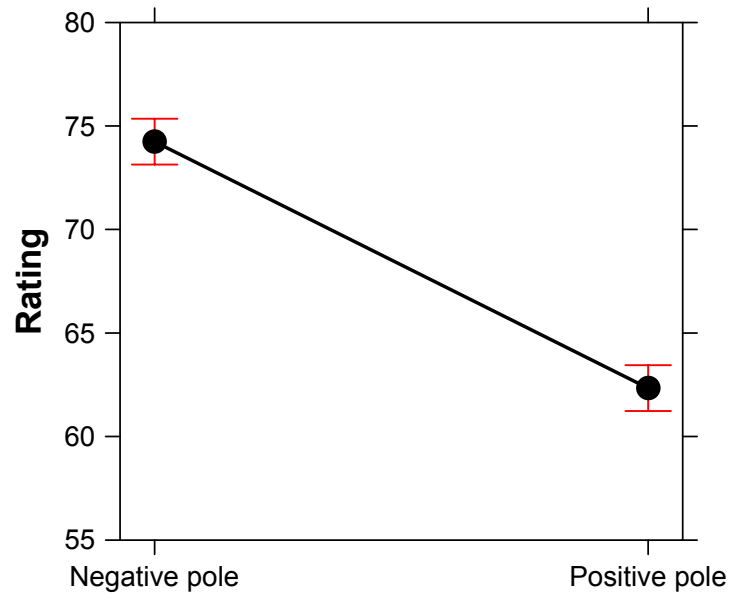

Type of information to information relating to the negative pole of a dimension, and second, whether this depended on how the information was communicated, that is, by means of opposite terms (BIP) or without opposite terms (UNI). The ratings given to the 4-item configuration subset were analyzed using a linear mixed model (Gaussian family) with type of communication (UNI, BIP), axes (H, R, T), and type of information (positive, negative) as fixed effects and participants as random effect (conditional- $\mathrm{R}^{2}$ index $=0.39$ ).

Two main effects emerged, while none of the interactions turned out to be significant. The first main effect concerns type of information $\left(\chi_{(1, \mathrm{~N}=470)}^{2}=2,233.665, p<0.0001\right.$; Figure 4A), and this is, in a sense, an obvious result. The items that comprised negative news (ie, those which referred to the negative pole) led to higher ratings - a perception of greater risk, a more serious illness and a greater degree of commitment - than those which related to positive news (ie, those which referred to the positive pole).

The second main effect is less obvious and is more central to the hypothesis being tested in this study. The ratings differed depending on the type of communication used $\left(\chi_{(1, \mathrm{~N}=470)}^{2}=38.097, p<0.0001\right)$. When polarized information was communicated by means of opposite terms (BIP), this led in general to higher ratings. This was true when information pertaining to both the positive and negative poles was concerned, as shown in Figure 4B. Indeed, the interaction between type of communication and type of information did not turn out to be significant: $\left(\chi_{(1, \mathrm{~N}=470)}^{2}=0.166, p=0.683\right)$.

A new analysis was conducted to further explore the differences between the two types of communication

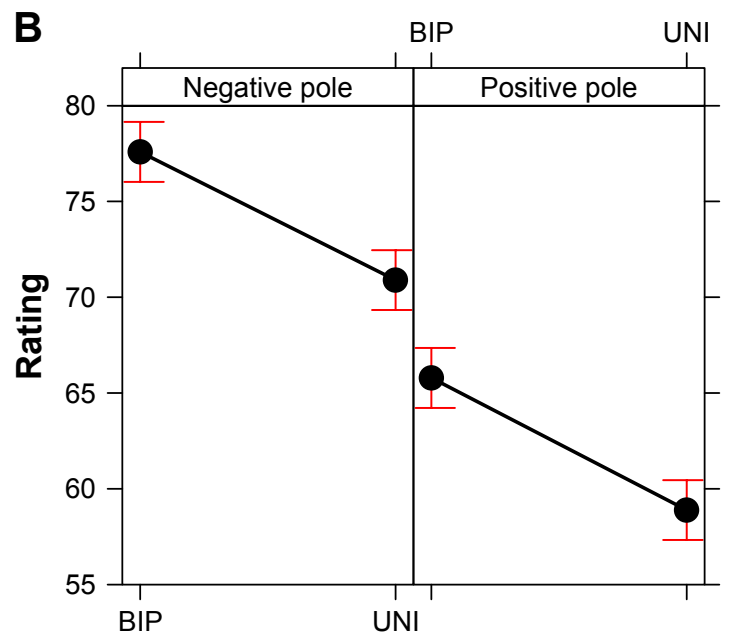

Type of communication

Figure 4 Plot of the main effect of type of information (negative pole, positive pole) on the ratings given by participants (A) and the interaction between type of communication (BIP, UNI) and type of information (B). Error bars represent a $95 \%$ confidence interval. Abbreviations: BIP, bipolar; UNI, unipolar. 
(BIP vs UNI). They were analyzed in more detail, and the ratings given to the corresponding BIP and UNI versions (ie, UNI positive pole vs BIP positive pole; UNI negative pole vs BIP negative pole) were matched item by item. This was done using Student's $t$-test after assessing the normality of distributions by means of Shapiro's test and the homogeneity/nonhomogeneity of variance by means of Levene's parametric and Kruskal-Wallis's non-parametric test. The outcomes of the tests were used to create a new categorical variable (items matching) on three levels: BIP $>$ UNI (when the Student's $t$-test turned out to be significant, with the UNI version receiving a significantly lower rating than the BIP version), BIP <UNI (when the Student's $t$-test turned out to be significant, with the UNI version receiving a significantly higher rating than the BIP version), UNI=BIP (when the Student's $t$-test turned out to be not significant, indicating that the two versions produced similar ratings). Mosaic plots ${ }^{58,59}$ were used to study and represent the frequency of the three categories of item matching (BIP $>$ $\mathrm{UNI}, \mathrm{BIP}=\mathrm{UNI}, \mathrm{BIP}<\mathrm{UNI}$ ), in association with the type of information (positive, negative) and axes (H, R, T) (Figure 5).

A mosaic plot represents 1 ) the observed frequencies of a contingency table by means of the size of the tiles - in Figure 5 , the raw frequencies are also reported by numbers on the tiles; 2) the interaction between variables by means of the asymmetrical non-alignment of the tiles; and 3) the significance of the difference between observed and expected frequencies according to a specific model (in our case a loglinear model of independence between variables) by means of the color of the tiles. The color of the tiles corresponds to Pearson residuals and the bars to the right of each mosaic show which color corresponds to residuals greater than the cutoff point $|2|$ (corresponding to a $p<0.05$ ).

As the size of the tiles in Figure 5 clearly reveals, in only very few cases (namely, in 11 out of the 60 matches considered, ie, 18\%) did the BIP and UNI versions of the

\section{Type of information (negative, positive) in UNI communication}

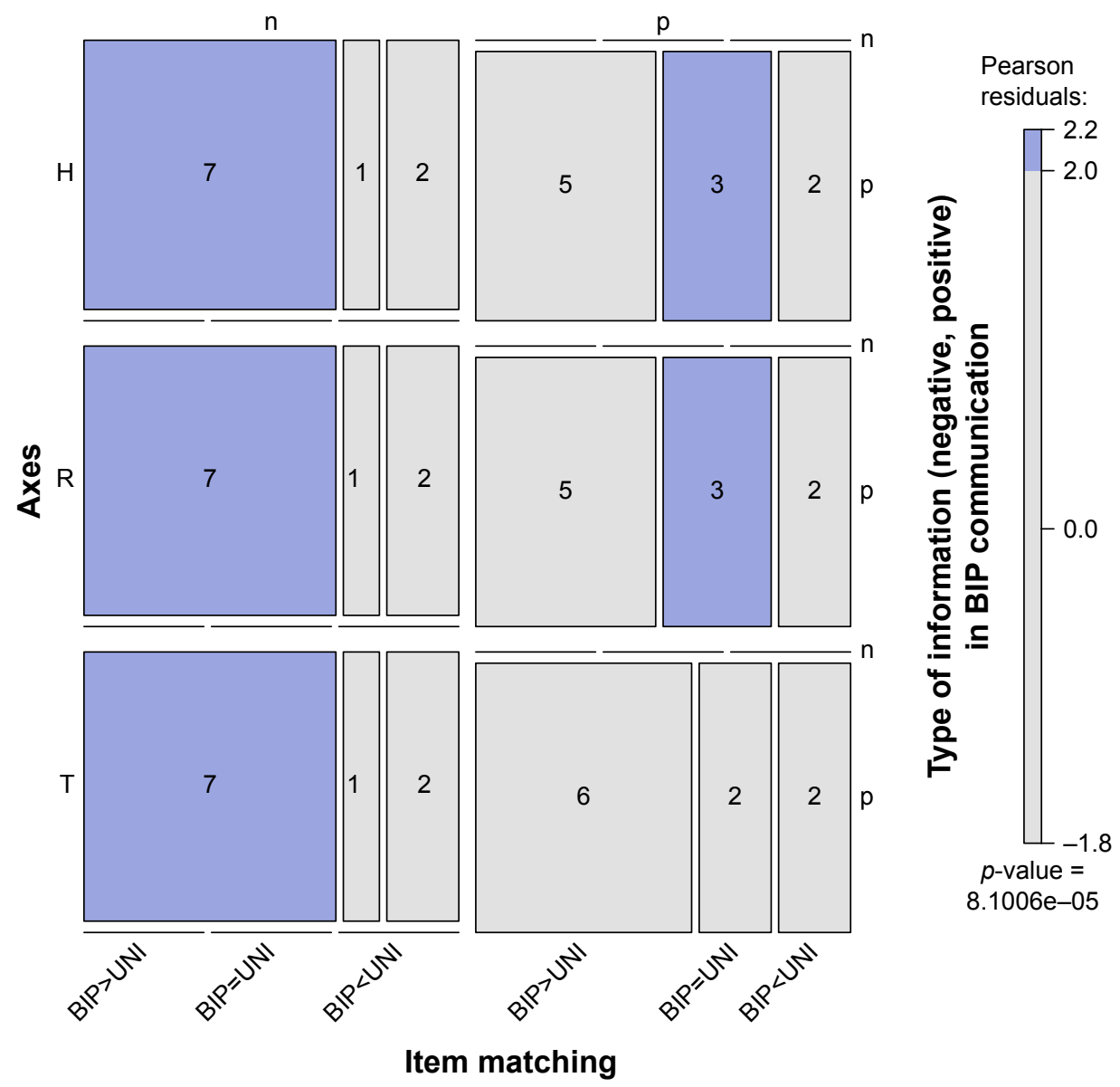

Figure 5 Mosaic plot showing the frequency of the three possible outcomes when corresponding items in the BIP and UNI versions of the questionnaire are matched, with 4-item configurations (BIP $>$ UNI, BIP=UNI, BIP $<$ UNI). Twenty matches for the ratings given to corresponding items ( 10 referring to the positive pole, $\mathrm{p}$; and 10 to the negative pole, $n$ ) were studied for each axis $(H, R$ and $T)$.

Abbreviations: BIP, bipolar; $\mathrm{H}$, health; R, risk; T, commitment to the treatment; UNI, unipolar. 
corresponding items have similar ratings $(\mathrm{BIP}=\mathrm{UNI})$. In the remaining $82 \%$ of matches (ie, 49 out of 60 ), "corresponding" polarized information produced different ratings. As indicated by the largest tiles in the mosaic, this generally meant that information communicated using opposites led to higher ratings than the "corresponding" unipolar version (ie, BIP>UNI). This finding emerged both when the positive pole ( $p$ in Figure 5) and the negative pole ( $\mathrm{n}$ in Figure 5) were concerned. However, as the significant Pearson's residuals indicate, this was even more true in the case of "bad news", where in fact BIP>UNI in $70 \%$ of the matches analyzed (ie, 21 out of 30). For example, "survival ratings associated with this tumor are low" prompted higher ratings in terms of $\mathrm{H}, \mathrm{R}$, or $\mathrm{T}$ than "survival ratings associated with this tumor are 30\%". Similarly, "the probability of side effects associated with the treatment are high" produced higher ratings than "the probability of side effects associated with the treatment is 1 out in a hundred", and "The side effects related to the treatment for this disease usually have an immediate onset" had higher ratings than "The side effects related to the treatment for this disease usually appear 1 day after the treatment".

Also in the case of "positive news", items in which opposites were used frequently rated higher than the unipolar equivalent, as indicated by the size of the tiles (BIP $>$ $\mathrm{UNI}=53 \%$, ie, 16 out of the 30 total item matches). However, the frequency of cases in which the ratings did not differ $(\mathrm{BIP}=\mathrm{UNI})$ increased for at least two of the axes, as indicated by the significant Pearson's residuals (BIP=UNI: $26 \%$ of the total number of matched items). For instance, "the probability of side effects associated with the treatment are low" got higher ratings in terms of $\mathrm{H}, \mathrm{R}$, or $\mathrm{T}$ than "the probability of side effects associated with the treatment is 1 in a hundred thousand". Similarly, "The treatment has high efficacy" got higher ratings than "The treatment has 70\% efficacy", whereas "Survival rates associated with this tumor are high" elicited a similar rating to "Survival rates associated with this tumor are $70 \%$ ".

\section{Analysis of the 3-item configuration type}

Investigating the "correspondence" between BIP and UNI ratings in 3-item configurations enabled us to assess people's understanding when the information given consists of opposites as compared to information which is not unbalanced toward one or the other pole (which we will refer to with the expression "non-polarized"). If non-polarized information is in effect understood as in between the poles, then the ratings to the UNI version are expected to be in-between those received by the two BIP version. If the non-polarized information is understood in terms of one or the other pole, then the ratings are expected to be similar to one of the two BIP versions, either the positive or the negative pole. If the non-polarized information is understood as more extreme than one or the other pole, then the ratings should be either higher or lower than both poles.

In order to study how the ratings varied for the three levels of communication/information studied (BIP positive, BIP negative, and UNI non-polarized), we first conducted a linear mixed model (Gaussian family) on the ratings given to the 3-item configuration subset. Type of communication/ information turned out to be significant $\left(\chi_{(2, \mathrm{~N}=470)}^{2}=1,947\right.$, $p<0.0001$; conditional- $\mathrm{R}^{2}$ index $=0.49$ ). As shown in Figure 6 and confirmed by post hoc tests, the ratings given for the non-polarized version were overall at an intermediate point between the two BIP versions, that is, lower than the average ratings associated with BIP negative (EST $=-6.523$, $\mathrm{SE}=1.15$, t-ratio $=5.672 ; p<0.0001 ; \mathrm{d}=0.516$ ) and higher than the average ratings associated with BIP positive $(\mathrm{EST}=6.160$, $\mathrm{SE}=1.15$, t-ratio $=5.356 ; p<0.0001 ; \mathrm{d}=0.487$ ).

Also in this case, it was possible to look more in detail at the relationship between the various communication types by matching the ratings given to the corresponding BIP and UNI versions item by item. Each rating given to a UNI item was matched with two BIP ratings, which corresponded, respectively, to the BIP positive (p) and BIP negative (n) items. We applied the same procedure described in the previous section, that is, we matched the ratings using Student's $t$-test and then used the outcomes of the tests to create a new categorical variable (item matching) which in this case had

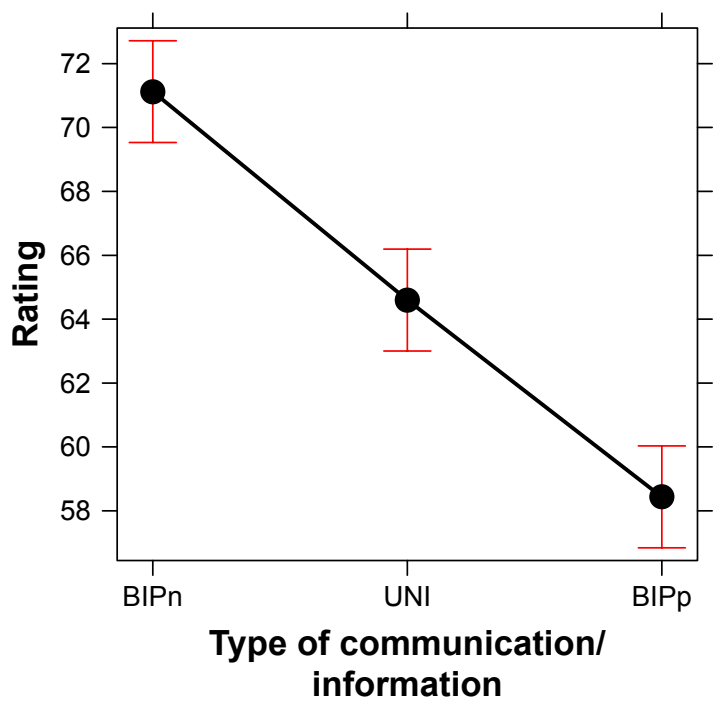

Figure 6 Plot of the main effect of type of communication/information - UNI $\mathrm{BIPn}$, and $\mathrm{BIPp}$ - on the ratings given by participants to the items with a 3 -item configuration. Error bars represent a $95 \%$ confidence interval.

Abbreviations: BIPn, bipolar negative; BIPp, bipolar positive; UNI, unipolar. 
seven levels, corresponding to the seven combinations found (BIPn, BIPp $<$ UNI; BIPn, BIPp=UNI; UNI <BIPn, BIPp; $\mathrm{BIPp}<\mathrm{UNI}<\mathrm{BIPn} ; \mathrm{BIPp}<\mathrm{UNI}=\mathrm{BIPn} ; \mathrm{BIPp}=\mathrm{UNI}<\mathrm{BIPn}$; $\mathrm{BIP} p=\mathrm{UNI}>\mathrm{BIPn})$. The frequency of these seven combinations in the three axes was then analyzed by means of the mosaic plot represented in Figure 7. As the color of the plot indicates, there was no significant interaction between the seven categories of item matching and the three axes. The size of the tiles reveals that there were two more frequent categories. One refers to the case in which the UNI version was in effect associated with an intermediate rating as compared to when the same information was given in terms of the BIP type communication referring to positive or negative poles (indicated by BIPp $<\mathrm{UNI}<\mathrm{BIPn}$ in Figure 7). This condition in-between the two opposites was found in $33.3 \%$ of the total number of matched items analyzed (ie, 14 out of 42). For example, a statement such as "the medical tests have revealed the presence of a nodule" led to significantly higher ratings than "the medical tests have revealed the presence of a benign nodule", but lower ratings than "the medical tests have revealed the presence of a malignant nodule".
Except for only seven cases $(16 \%)$ in which the UNI version led to lower or higher ratings than both of the BIP versions (indicated by BIPn, BIPp $<\mathrm{UNI}$ and $\mathrm{UNI}<\mathrm{BIPn}$, BIPp in Figure 7), in all other cases the participants reacted to the non-polarized UNI version in the same way as when the information was given in terms of one or the other pole, which in the majority of cases was the positive pole. The second most frequent category (ie, $26 \%$ of the total number of matches analyzed) refers to 11 cases in which the UNI version was understood as "positive news" (indicated by BIPp=UNI $<$ BIPn in Figure 7). This means that, for example, the statement "This is a possible treatment" elicited ratings which were similar to those relating to the statement "This treatment is recommended", and both the ratings were lower than those elicited by the statement "This treatment is necessary". In the same way, the ratings for "Once the treatment is completed some people need assistance from a third party (family or other)" were similar to those for "Once the treatment is completed, no assistance is needed from a third party (family or other)". The statement "Once the treatment is completed, there is need of assistance from a third party (family or other)" was rated higher.

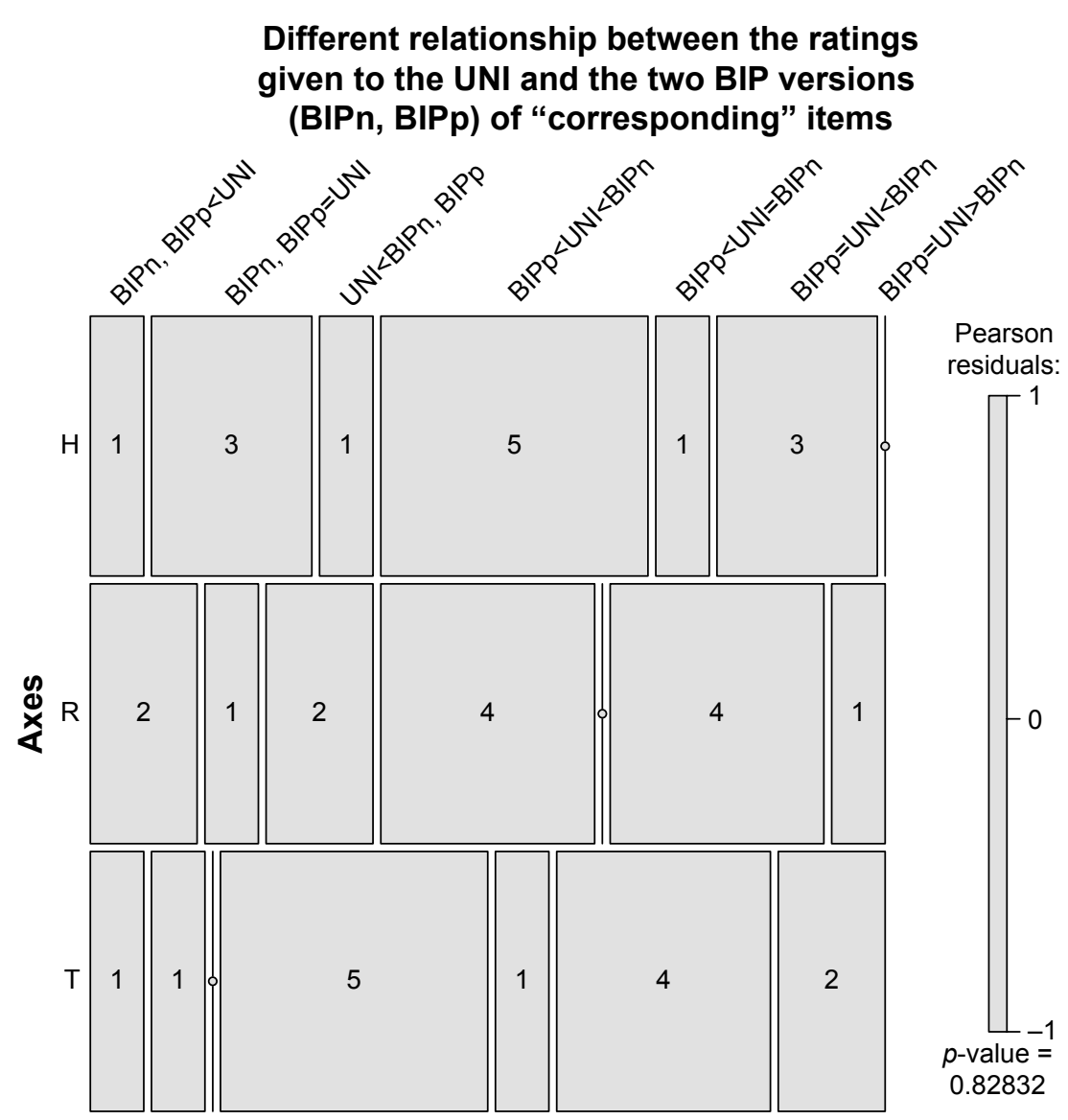

Figure 7 Mosaic plot showing the frequency of the seven outcomes of the matching between corresponding items in the BIP and UNI polar versions of the questionnaire, with 3-item configurations. Fourteen matches were studied for each axis $(H, R$ and $T)$.

Abbreviations: BIP, bipolar; BIPn, bipolar negative; BIPp, bipolar positive; H, health; R, risk; T, commitment to the treatment; UNI, unipolar. 

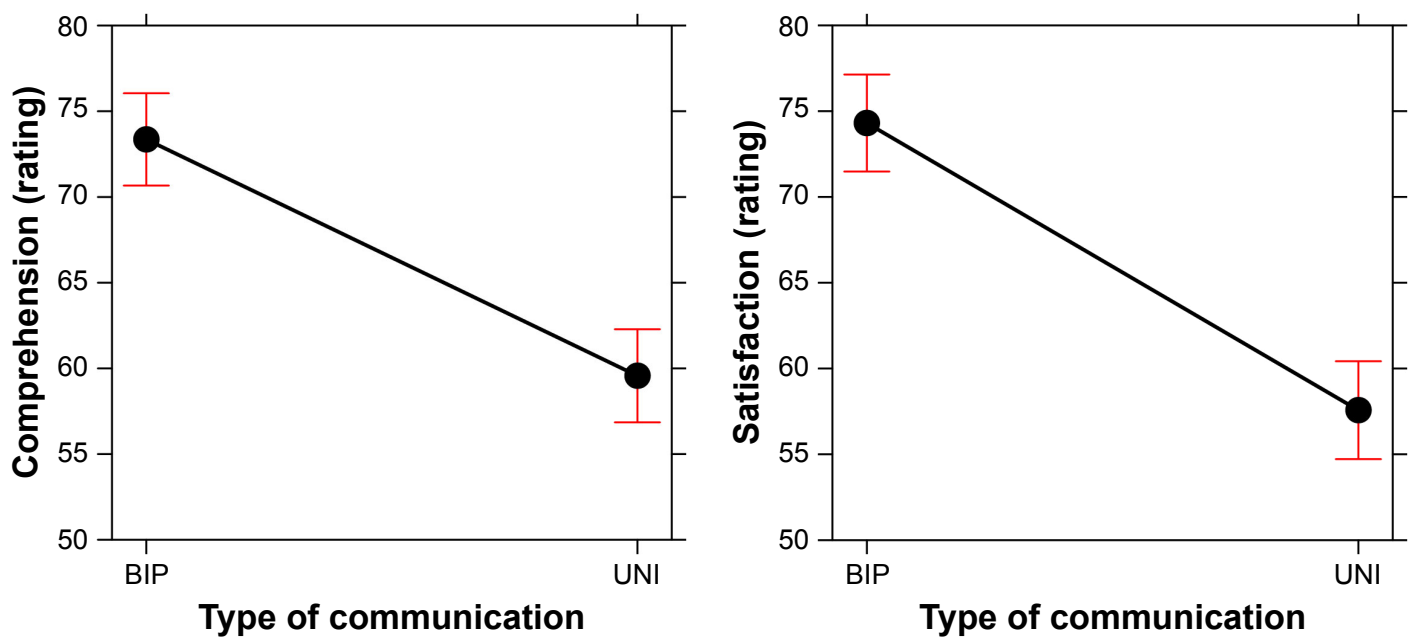

Figure 8 Mean ratings (self-reported) for comprehension and satisfaction with the way the information was communicated - either BIP or UNI. Error bars represent a $95 \%$ confidence interval.

Abbreviations: BIP, bipolar; UNI, unipolar.

\section{Self-reported comprehension and satisfaction with the communication}

Two separate LMMs (Gaussian family), with type of communication (UNI, BIP) and gender (male, female) as fixed effects and participants as a random effect, were conducted to analyze the final ratings for comprehension of the information communicated and satisfaction with the way it was communicated, as expressed by the participants at the end of the questionnaire (the conditional- $\mathrm{R}^{2}$ index of the model was 0.94 for comprehension and 0.92 for satisfaction). For both judgments, a significant effect of type of communication emerged (with no difference for males and females). As shown in Figure 8, the participants reported higher average ratings for comprehension with the bipolar as compared to the UNI form of communication $\left(\chi_{(1, \mathrm{~N}=470)}^{2}=49.929\right.$, $p<0.0001, \mathrm{EST}=13.883, \mathrm{~d}=0.582$ ). The same hold for selfreported level of satisfaction $\left(\chi_{(1, \mathrm{~N}=470)}^{2}=66.658, p<0.0001\right.$, EST $=16.902, d=0.700)$. A strong positive correlation between ratings of comprehension and ratings of satisfaction emerged in both the questionnaires (UNI: $r=0.81$; BIP: $r=0.79$ ).

\section{Final remarks}

In a worldwide survey on cancer patients, around $40 \%$ of those surveyed desired more knowledge and involvement concerning decision making. ${ }^{60}$ The informed consent form is a crucial document in that it enables patients to make an informed decision. ${ }^{61}$ Providing accurate information does not suffice if it is provided in a language that people do not understand. A plethora of previous studies have demonstrated that a large number of people did not fully understand the basic information regarding clinical trials $\mathrm{s}^{6,7,16,62}$ and that those with a lower standard of literacy were particularly exposed to the risk of poor comprehension..$^{9,63}$ The findings presented in this paper add to previous studies that confirmed positive effects in terms of the degree of comprehension due to simplifying the informed consent form. ${ }^{10,18,64-68}$ In the present study, however, instead of simplifying the form in terms of reducing its length, using plain language and short sentences, providing diagrams and pictures and making use of formatting techniques (such as a bold font, highlighting, and bullet points), we focused on whether opposites can play a role. In particular, we explored how communicating in terms of opposites (in the context of information relating to informed consent for oncology trials) rather than avoiding polarization (3-item configuration) or masking polarization (3-item configuration) impacts on people's understanding and their perception of being healthy-ill, at low-high risk, and of the high-low commitment required to undergo any treatment necessary.

The results demonstrated, in general, that the ratings given by participants depended on which of the two forms of communication types was used. First, when polarized information was concerned (ie, items with a 4-item configuration), speaking in terms of opposites led to higher ratings, both when "bad" and "good" news was given. Taking into account the fact that positive poles in any case concerned the existence of a disease, active commitment and perception of a certain amount of illness and risk are important. The ratings associated with the positive pole expressed in BIP terms were however moderate and in any case lower than those associated with the negative pole, however, the latter 
was expressed. This confirms that we should interpret this higher rating associated with the BIP version not in terms of an exaggerated reaction, but rather of a positive activation.

Second, in the case of the 3-item configuration, when nonpolarized information was provided, the UNI version was not univocally interpreted. Sometimes it led to an intermediate rating such as when the information given was in between bad and good news and sometimes it was understood as pertaining to one of the two poles, which in the majority of cases was the "positive pole". One can think of this result in terms of a bias toward an optimistic interpretation of nonpolarized information, but it might also indicate a bias toward underestimation of the severity of the disease.

Lastly, a difference emerged in terms of the participants' self-reported impression of whether they understood the information provided and whether they were satisfied with the form of communication used. Their impressions in both the cases were more favorable for the BIP communication type as compared to the UNI version. It should be noted that in both the versions of the questionnaire (UNI and BIP), the statements were expressed in simple everyday language which avoided technical terms. Therefore, the difference that was found has nothing to do with the participants finding it difficult to understand the language used. It seems to suggest rather that a better isomorphism was found between the way in which the information was presented in the bipolar version and the way in which it was processed (ie, understood) by the listener. Of course, we are well aware that these results do not mean that the idea the patient gets of the gravity of the situation and of the commitment required by the treatment (subjective comprehension) is closer to what the doctor is trying to convey (objective understanding). A different study would be necessary to test this by collecting ratings from a sample of doctors in addition to a sample of patients. However, since encouraging patients to take care of their health is an important aim for a doctor and the patient's understanding is important in order for he/ she to be actively engaged in the process, ${ }^{14}$ the results of this study represent an important starting point.

Other limitations of our study are that 1) our participants were adults (either young or middle aged) in a simulated context and not real patients (of various ages) in a real diagnostic context; using students as a sample and simulating cases of course limit extrapolation to actual clinical contexts; 2) our participants were Italian, and it cannot be excluded that patient preferences and understanding in other countries might be different; 3) individual differences and contextual differences (relating to the family of the patient and to various social aspects) are inevitable components of the complex story relating to coping with a real disease. Further studies are therefore needed which extend the investigation crosslinguistically and use real clinical settings. However, the aim of this study was to explore the hypothesis that another reasonable aspect to consider in terms of how to encourage active decision making and improve communication and comprehension of information relating to informed consent in medical contexts is linked to the cognitive and linguistic primacy of opposites in natural languages ${ }^{35,39-42}$ as well as in human perception and conceptualization. ${ }^{28,31,33}$ We consider the findings collected in this initial study (with all the abovementioned limitations) to be encouraging.

\section{Acknowledgments}

We wish to thank Ricardo Pietrobon for stimulating us to develop this research, Michael Kubovy for his input and suggestions on a previous version of this paper, and the undergraduate students, Nasko Bressan, Annachiara Teboni, and Eliana Orlandini, for their help in data collection.

\section{Disclosure}

The authors report no conflicts of interest in this work.

\section{References}

1. European Commission Health and Consumers Directorate-General. Revision of the Clinical Trials Directive 2001/20/EC. Brussels, 09/02/2011. $\mathrm{SANCO} / \mathrm{C} / 8 / \mathrm{PB} / \mathrm{SF} \mathrm{D}(2011)$ 143488. Available from: https://ec.europa. eu/health/sites/health/files/files/clinicaltrials/ctresp_2011-06/leti_ pharma.pdf. Accessed March 16, 2018.

2. Aaronson NK, Visser-Pol E, Leenhouts GH, et al. Telephone-based nursing intervention improves the effectiveness of the informed consent process in cancer clinical trials. J Clin Oncol. 1996;14(3):984-996.

3. Brown RF, Butow PN, Ellis P, Boyle F, Tattersall MH. Seeking informed consent to cancer clinical trials: describing current practice. Soc Sci Med. 2004;58(12):2445-2457.

4. Jenkins V, Fallowfield L, Souhami A, Satwell M. How do doctors explain randomised clinical trials to their patients? Eur J Cancer. 1999; 35(8):1187-1193.

5. Hietanen P, Aro AR, Holli K, Absetz P. Information and communication in the context of a clinical trial. Eur J Cancer. 2000;36(16): 2096-2104.

6. Holland J, Browman G, McDonald M, Saginur R. Protecting human research participants: reading vs understanding the consent form. $J$ Natl Cancer Inst. 2013;105(13):927-928.

7. Paasche-Orlow MK, Taylor HA, Brancati FL. Readability standards for informed consent forms as compared with actual readability. $N$ Engl $J$ Med. 2003;348(8):721-726.

8. Schumacher A, Sikov WM, Quesenberry MI, et al. Informed consent in oncology clinical trials: a Brown University Oncology Research Group prospective cross-sectional pilot study. PLoS One. 2017;12(2): e0172957.

9. Breese P, Burman W, Goldberg S, Weis S. Education level, primary language, and comprehension of the informed consent process. J Empir Res Hum Res Ethics. 2007;2(4):69-79.

10. Dresden GM, Levitt MA. Modifying a standard industry clinical trial consent form improves patient information retention as part of the informed consent process. Acad Emerg Med. 2001;8(3):246-252. 
11. Joffe S, Cook EF, Clearly PD, Clark JW, Weeks JC. Quality of informed consent: a new measure of understanding among research subjects. J Natl Cancer Inst. 2001;93(2):139-147.

12. Brandberg Y, Johansson H, Bergenmar M. Patients' knowledge and perceived understanding - associations with consenting to participate in cancer clinical trials. Contemp Clin Trials Commun. 2016; 2(15):6-11.

13. Miller SM, Hudson SV, Egleston BL, et al. The relationships among knowledge, self-efficacy, preparedness, decisional conflict, and decisions to participate in a cancer clinical trial. Psychooncology. 2013; 22(3):481-489.

14. Pravettoni G, Cutica I, Righetti S, Mazzocco K. Decisions and the involvement of cancer patient survivors: a moral imperative. J Healthc Leadersh. 2016;8:121-125.

15. Byrne MM, Kornfeld J, Vanderpool R, Belanger M. Discussions of cancer clinical trials with NCI's Cancer Information Service. J Health Commun. 2012;17(3):319-337.

16. Byrne MM, Tannenbaum SL, Gluck S, Hurley J, Antoni M. Participation in cancer clinical trials: why are patients not participating? Med Decis Making. 2013;34(1):116-126.

17. Des Jarlais DC, Paone D, Milliken J, et al. Audio-computer interviewing to measure risk behaviour for HIV among injecting drug users: a quasi-randomised trial. Lancet. 1999;353(9165):1657-1661.

18. Flory J, Emanuel E. Interventions to improve research participants' understanding in informed consent for research: a systematic review. JAMA. 2004;292(13):593-601.

19. Jacobsen PB, Wells KJ, Meade CD, et al. Effects of a brief multimedia psychoeducational intervention on the attitudes and interest of patients with cancer regarding clinical trial participation: a multicenter randomized controlled trial. J Clin Oncol. 2012;30(20):2516-2521.

20. Kass NE, Taylor HA, Ali J, Hallez K, Chaisson L. A pilot study of simple interventions to improve informed consent in clinical research: feasibility, approach, and results. Clin Trials. 2015;12(1) 54-66.

21. Krishnamurti T, Argo N. A patient-centered approach to informed consent: results from a survey and randomized trial. Med Decis Making. 2016;36(6):726-740.

22. Nishimura A, Carey J, Erwin PJ, Tilburt JC, Murad MH, McCormick JB. Improving understanding in the research informed consent process: a systematic review of 54 interventions tested in randomized control trials. BMC Med Ethics. 2013;14(28):14-28.

23. Perlis TE, Des Jarlais DC, Friedman SR, Arasteh K, Turner CF. Audiocomputerized self-interviewing versus face-to-face interviewing for research data collection at drug abuse treatment programs. Addiction 2004;99(7):885-896.

24. Synnot A, Ryan R, Prictor M, Fetherstonhaugh D, Parker B. Audiovisual presentation of information for informed consent for participation in clinical trials. Cochrane Database Syst Rev. 2014;9(5):CD003717.

25. Stunkel L, Benson M, McLellan L, et al. Comprehension and informed consent: assessing the effectiveness of a short consent form. IRB. 2010;32(4):1-9.

26. Bergenmar M, Johansson H, Wilking N. Levels of knowledge and perceived understanding among participants in cancer clinical trials factors related to the informed consent procedure. Clin Trials. 2011; 8(1):77-84.

27. Bianchi I, Burro R, Torquati S, Savardi U. The middle of the road: perceiving intermediates. Acta Psychol. 2013;144(1):121-135.

28. Bianchi I, Savardi U. The Perception of Contraries; Roma: Aracne; 2008.

29. Bianchi I, Savardi U, Burro R. Perceptual ratings of opposite spatial properties: do they lie on the same dimension? Acta Psychol. 2011;138(3) 405-418.

30. Burro R. To be objective in experimental phenomenology: a psychophysics application. SpringerPlus. 2016;5(1):1720.

31. Bianchi I, Paradis C, Burro R, van de Weijer J, Nyström M, Savardi U. Identification of poles and intermediates by eye and by hand. Acta Psychol. 2017;180:175-189.
32. Bianchi I, Savardi U, Kubovy M. Dimensions and their poles: a metric and topological theory of opposites. Lang Cogn Process. 2011;26(8): 1232-1265.

33. Gärdenfors P. Conceptual Spaces: The Geometry of Thought. Cambridge: The MIT Press; 2000.

34. Gärdenfors P. The Geometry of Meaning. Semantics Based on Conceptual Spaces. Cambridge: The MIT Press; 2014.

35. Miller GA. The Science of Words. New York: Scientific American Library; 1996.

36. Jones S, Murphy ML, Paradis C, Willners C. Antonyms in English: Construals, Constructions and Canonicity. Cambridge: Cambridge University Press; 2012.

37. Paradis C, Hudson J, Magnusson U, editors. The Construal of Spatial Meaning: Windows into Conceptual Space. Oxford: Oxford University Press; 2013.

38. Paradis C, Willners C, Jones S. Good and bad opposites: using textual and psycholinguistic techniques to measure antonym canonicity. Ment Lex. 2009;4(3):380-429.

39. Croft W, Cruse DA. Cognitive Linguistics. Cambridge: Cambridge University Press; 2004.

40. Cruse DA, Pagona T. Towards a cognitive model of antonymy. Lexicology. 1995;1:113-141.

41. Fellbaum C. Co-occurrence and antonymy. Int J Lex. 1995;8(4) 281-303.

42. Jones S. Antonymy: A Corpus-Based Perspective. London: Routledge; 2002.

43. Murphy L. Semantic Relations and the Lexicon: Antonyms, Synonyms and Other Semantic Paradigms. Cambridge: Cambridge University Press; 2003.

44. Casasola M. The development of infants' spatial categories. Curr Dir Psychol Sci. 2008;17:21-25.

45. Casasola M, Cohen LB, Chiarello E. Six-month-old infants' categorization of containment spatial relations. Child Dev. 2003;(74):679-693.

46. Hespos SJ, Spelke ES. Conceptual precursors to language. Nature. 2014;430(6998):453-456.

47. McDonough L, Choi S, Mandler JM. Understanding spatial relations: flexible infants, lexical adults. Cog Psychol. 2003;46(3):229-259.

48. Quinn PC, Cummins M, Kase J, Martin E, Weisman S. Development of categorical representations for above and below spatial relations in 3- to 7-month-old infants. Dev Psychol. 1996;32(5):942-950.

49. Bianchi I, Savardi U, Burro R, Martelli MF. Doing the opposite to what another person is doing. Acta Psychol. 2014;151:117-133.

50. Kelso JAS, Engstrøm D. The Complementary Nature. Cambridge: The MIT Press; 2006.

51. Savardi U, editor. The Perception and Cognition of Contraries. Milano: Mc-Graw Hill; 2009.

52. Bates D, Machler M, Bolker BM, Walker SC. Fitting linear mixedeffects models using lme4. J Stat Softw. 2015;67:1-48.

53. Lenth RV. Least-squares means: the R package lsmeans. J Stat Softw. 2016;69(1):1-33.

54. Burro R, Raccanello D, Pasini M, Brondino M. An estimation of a nonlinear dynamic process using latent class extended mixed models: affect profiles after terrorist attacks. Nonlinear Dynamics Psychol Life Sci. 2018;22(1):35-52.

55. Kuznetsova A, Bruun BP, Haubo BCR. lmerTest: tests in linear mixed effects models. $R$ package version 2.0-32 [serial on the Internet]. 2016. Available from: https://CRAN.R-project.org/package=lmerTest. Accessed November 2, 2017.

56. Cohen J. Statistical Power Analysis for the Behavioral Sciences. 2nd ed. New York: Academic Press; 1988.

57. Nakagawa S, Schielzeth H. A general and simple method for obtaining R2 from generalized linear mixed-effects models. Methods Ecol Evol. 2013;4(2):133-142.

58. Friendly M. Mosaic displays for multi-way contingency tables. J Am Stat Ass. 1994;89:190-200.

59. Friendly M. Visualizing Categorical Data. Carey: SAS Institute; 2000 . 
60. Alston C, Paget L, Halvorson G, et al. Communicating with Patients on Health Care Evidence. Discussion Paper, Institute of Medicine, Washington, DC; 2012. Available from: https://nam.edu/wp-content/ uploads/2015/06/VSRT-Evidence.pdf

61. Rao KHS. Informed consent: an ethical obligation or legal compulsion? J Cutan Aesthet Surg. 2008;1(1):33-35.

62. Cheung WY, Pond GR, Heslegrave RJ, Enright K, Potanina L, Siu LL. The contents and readability of informed consent forms for oncology clinical trials. Am J Clin Oncol. 2010;33(4):387-392.

63. Sudore RL, Landefeld CS, Williams BA, Barnes DE, Lindquist K, Schillinger D. Use of a modified informed consent process among vulnerable patients: a descriptive study. J Gen Intern Med. 2006;21(8): $867-873$.

64. Dormandy E, Tsui EY, Marteau TM. Development of a measure of informed choice suitable for use in low literacy populations. Patient Educ Couns. 2007;66:278-295.
65. Choi J. Literature review: using pictographs in discharge instructions for older adults with low-literacy skills. J Clin Nurs. 2011;20: 2984-2996.

66. Tamariz L, Palacio A, Robert M, et al. Improving the informed consent process for research subjects with low literacy: a systematic review. J Gen Intern Med. 2013;28:121-126.

67. Davis TC, Holcombe RF, Berkel HJ, et al. Informed consent for clinical trials: a comparative study of standard versus simplified forms. J Natl Cancer Inst. 1998;90:668-674.

68. Kim EJ, Kim SH. Simplification of inform consent improves understanding of informed consent information in clinical trials regardless of health literacy. Clin Trials. 2015;12(3):232-236. 


\section{Supplementary material}

Table SI Bipolar and unipolar items used in the study in English with Italian translation in square brackets

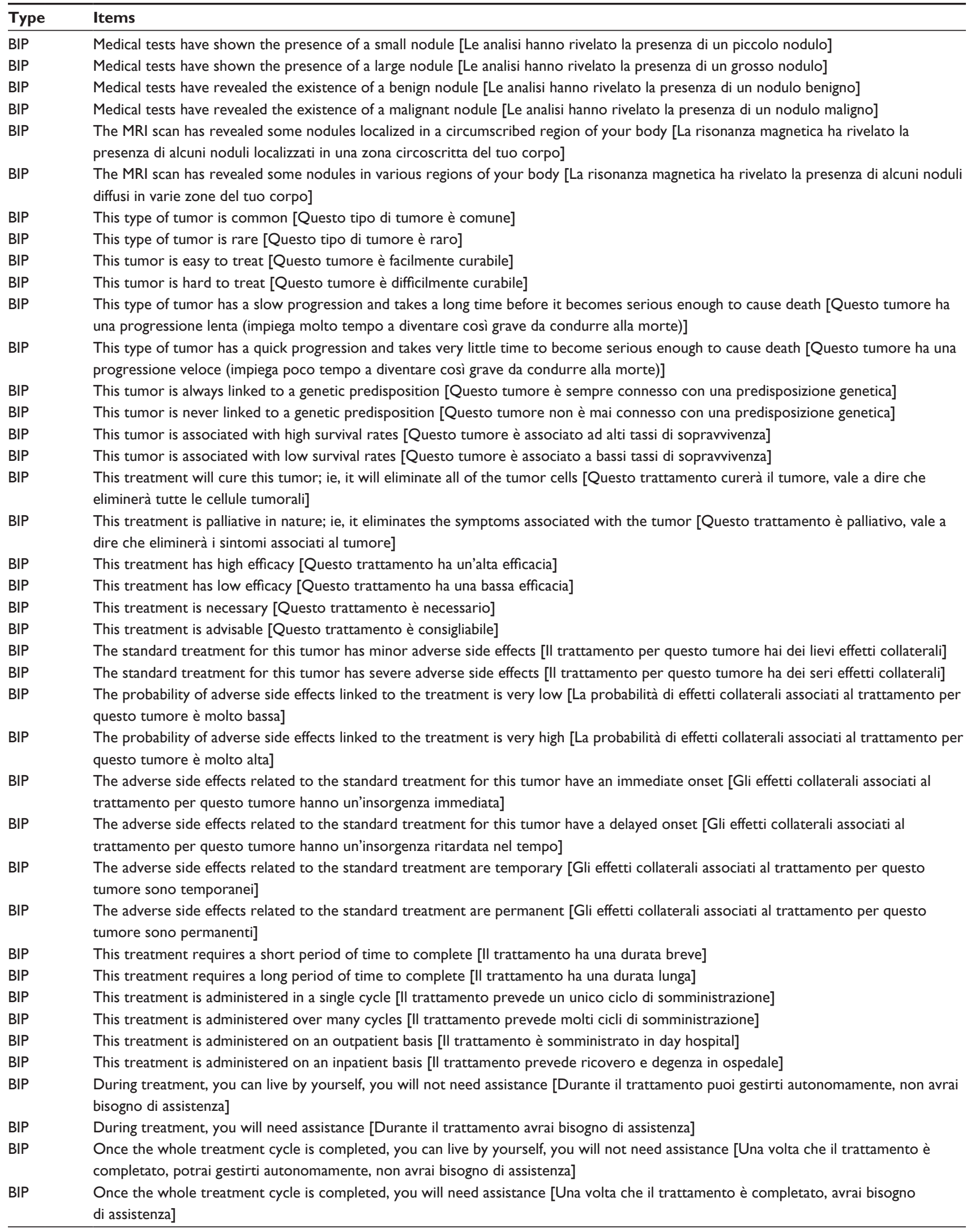


Table SI (Continued)

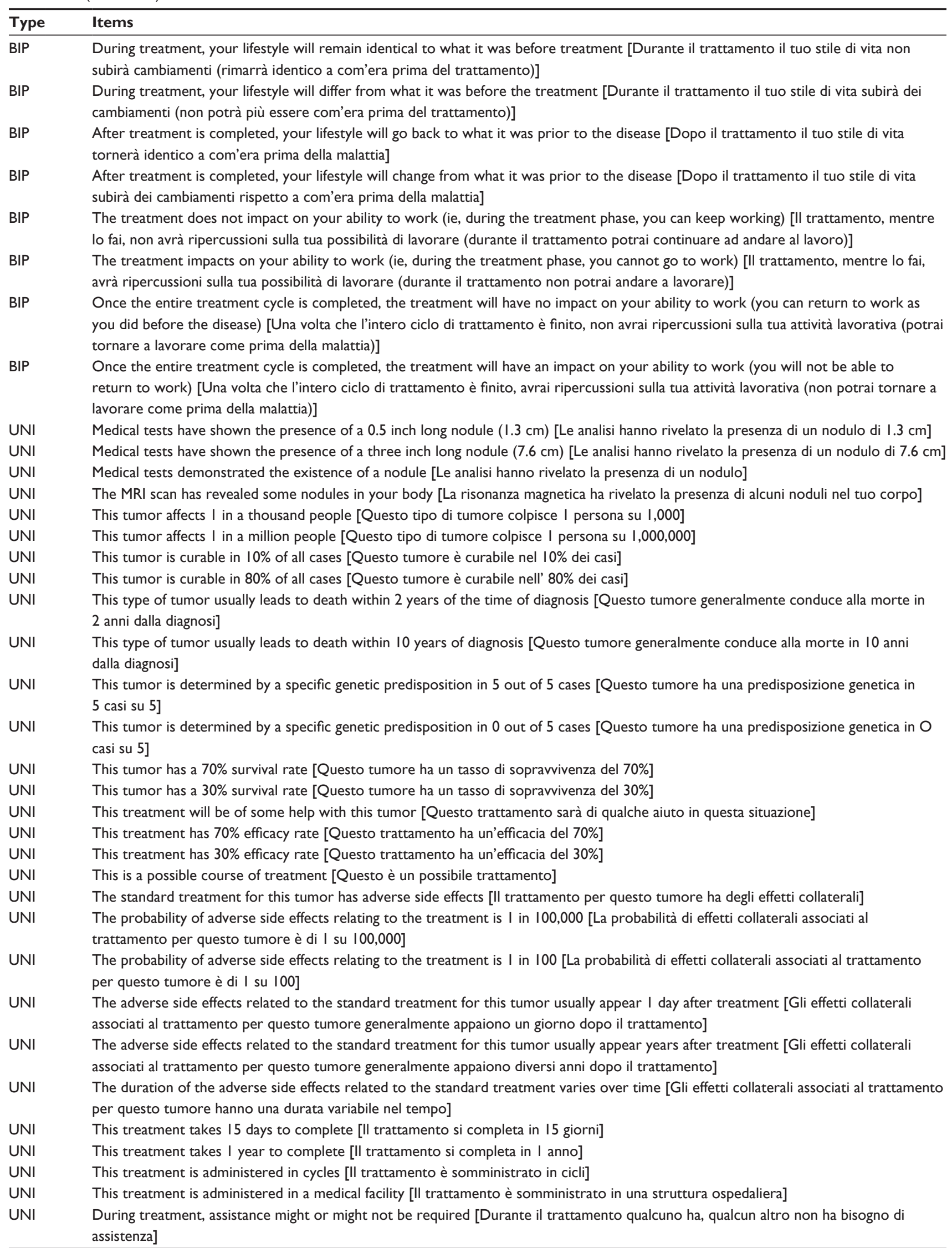


Table SI (Continued)

Type Items

UNI Once the whole treatment cycle is completed, assistance might or might not be required [Una volta che il trattamento è completato qualcuno ha, qualcun altro non ha bisogno di assistenza]

UNI During treatment, your lifestyle might or might not be affected [Durante il trattamento il tuo stile di vita potrebbe subire dei cambiamenti (qualcuno riesce a fare la vita che faceva prima, qualche altro no)]

UNI After treatment is completed, your lifestyle might or might not change from what it was prior to the disease [Dopo il trattamento il tuo stile di vita potrebbe subire dei cambiamenti rispetto a com'era prima della malattia (qualcuno riesce a fare la vita che faceva prima, qualche altro no)]

UNI The treatment might or not impact on your ability to work (during the treatment phase) [II trattamento, mentre lo fai, potrebbe influire sulla tua possibilità di andare a lavorare (qualcuno durante il trattamento non riesce ad andare a lavorare, qualcuno invece si)]

UNI Once the entire treatment cycle is completed, the treatment might or not impact on your ability to work... [Una volta che l'intero ciclo di trattamento è finito, potresti avere (ma anche no) ripercussioni sulla tua attività lavorativa (qualcuno non riesce ad tornare a lavorare come prima, qualcuno invece si)]

Abbreviations: BIP, bipolar; MRI, magnetic resonance imaging; UNI, unipolar.

\section{Publish your work in this journal}

Patient Preference and Adherence is an international, peer-reviewed, open access journal that focuses on the growing importance of patient preference and adherence throughout the therapeutic continuum. Patient satisfaction, acceptability, quality of life, compliance, persistence and their role in developing new therapeutic modalities and compounds to optimize clinical outcomes for existing disease states are major areas of interest for the journal. This journal has been accepted for indexing on PubMed Central. The manuscript management system is completely online and includes a very quick and fair peer-review system, which is all easy to use. Visit http://www. dovepress.com/testimonials.php to read real quotes from published authors.

\footnotetext{
Submit your manuscript here: http://www.dovepress.com/patient-preference-and-adherence-journal
} 